\title{
Dimensões históricas das relaç̃ões entre educação e Serviço Social: elementos para uma revisão crítica
}

\author{
Historical dimensions of relations between education \\ and Social Work: elements for a critical review
}

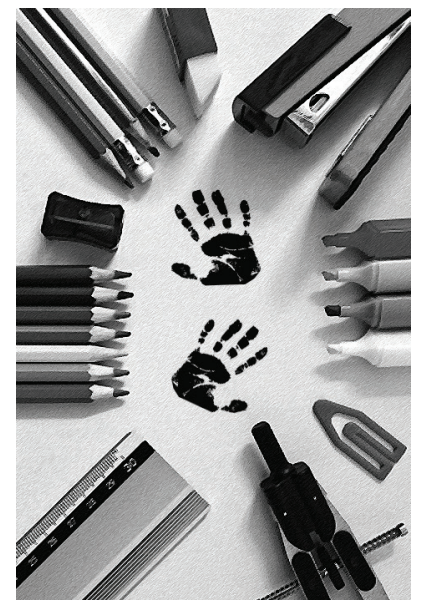

\section{Marta von Dentz Roberto Rafael Dias da Silva**}

Resumo: Este estudo apresenta um conjunto de referências históricas acerca da relação Educação e Serviço Social, objetivando resgatar interfaces de origem das duas áreas do conhecimento e perceber como foi se estabelecendo a articulação entre a Educação como política pública e sua vinculação ao Serviço Social. Tomamos como materialidade investigativa referenciais teóricos da Educação e do Serviço Social e indicamos que, na constituição histórica das relações entre ambos, ocorrem significativas mudanças de ênfase nas racionalidades políticas e nas formas de intervenção, muito embora o debate sobre as proteções sociais e o combate às desigualdades seja uma constante.

Palavras-chave: Educação. Serviço Social. Proteção social.

\begin{abstract}
This study presents a set of historical about the relationship Education and Social Work, aiming to rescue source interfaces of the two areas of knowledge and notice how it was establishing the link between Education as Public Policy and its linkage to the Social Work. We take as reference theoretical investigative materiality of Education and Social Work and indicate that, in the historical development of relations between both occur significant changes of emphasis in political rationalities and forms of intervention, although the discussion on social protection and the tackling inequalities it is a constant.
\end{abstract}

Keywords: Education. Social Work. Social protection.

* Mestranda em Educação pela Universidade Federal da Fronteira Sul (UFFS); bacharel em Serviço Social pela Universidade do Oeste de Santa Catarina/SC (Unoesc), Brasil.E-mail: martavondentz@gmail.com.

** Doutor em Educação pela Universidade do Vale do Rio dos Sinos; professor adjunto na Área de Fundamentos da Educação na Universidade Federal da Fronteira Sul, campus Erechim/SC, Brasil. E-mail: robertosilva@uffs.edu.br. 


\section{Introdução}

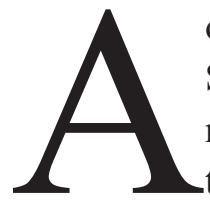

o buscar construir uma abordagem sobre a historicidade do Serviço Social na Educação brasileira, destaca-se a priori que adentrar nessa temática e, por conseguinte, espraiar uma apreensão consistente das relações existentes entre elas demanda cautela, aprofundamento daquilo que o Serviço Social e a Educação já possuem de acúmulo histórico e, simultaneamente, perceber as crepitações desse acúmulo nas configurações societárias contemporâneas. Para isso, parte-se da ideia de que o presente não é apenas o contemporâneo. É também “o esforço de reentender o surgimento do mais contemporâneo, reconstruindo o sistema das transformações de que a situação atual é herdeira", um efeito de herança, sendo que a memória de tal herança é necessária para compreender e agir no hoje (Castel, 1998, p. 23).

No desafio de construir essa historicidade, Koike (2009) aponta algumas exigências atuais para a formação dos profissionais de Serviço Social, discorre sobre os desafios da precarização do trabalho, dos direitos sociais, da educação e da seguridade social, sendo que, a partir de 2000, percebe-se uma regressão e uma despolitização dos processos sociais. Apesar de a autora mobilizar suas pontuações para a formação profissional de assistentes sociais, tentando salvaguardar conquistas conferentes à legitimidade intelectual específica, há um aspecto que pode contribuir nesse estudo, a nomeada "astúcia da história", em que a direção social atual provoca tensões constantes, num sentido de recusa à crítica (Koike, 2009, p. 215). Tomando essa condição, "astúcia da história", como uma metáfora, outros entendimentos são possíveis de ser catalisados, pois "se o real cria e repõe permanentemente desafios e formas de luta, assegura também renovadas possibilidades", e é nessa perspectiva que reside tal astúcia histórica (Idem). Dessa forma, as mobilizações dessa analítica sinalizam para a importância de perceber os aspectos históricos das temáticas enfatizadas, não como algo linear, naturalizado, mas como algo em movimento, criado e recriado.

Esse modo de ver a história evoca a percepção daquilo que Carvalho (2002), ao analisar o processo descontínuo e limitado da conquista dos direitos sociais, políticos e civis no cenário brasileiro, apontando suas especificidades históricas, denomina como "peso do passado", no longo caminho para a cidadania no Brasil. Ou, então, em "pontos e bordados" dos escritos sobre história 
e política, o referido autor pontua as variações das imagens da nação brasileira ao longo do tempo, das visões da elite e dos setores dominantes. Mais concretamente, desde 1822 até 1945, três imagens de nação foram sendo construídas pelas elites políticas e intelectuais: "A primeira poderia ser caracterizada pela ausência do povo, a segunda pela visão negativa do povo, a terceira pela visão paternalista do povo. Em nenhuma o povo faz parte da construção da imagem nacional. Eram nações apenas imaginadas" (Carvalho, 1998, p. 233).

As sinalizações antepostas oportunizam adentrar naquilo que se pode chamar de "ênfase analítica" deste estudo: no Brasil, especificamente, perdura ao longo da história "a incapacidade do sistema representativo de produzir resultados que impliquem a redução da desigualdade [...]. A desigualdade é a escravidão de hoje, o novo câncer que impede a constituição de uma sociedade democrática" (Carvalho, 2002, p. 229). E ainda, nas configurações do novo capitalismo, a desigualdade vem se caracterizando pela "distância social", de modo que, quanto maior a distância, quanto menos for sentido o vínculo entre os desiguais, maior será a desigualdade social existente entre eles (Sennett, 2006, p. 55).

Convém respaldar a menção dada à ênfase analítica escolhida: as desigualdades que, de forma mais ou menos intensa, vêm demarcando a história. Ao abordá-la, faz-se referência à "questão social" compreendendo seus desdobramentos e suas "metamorfoses" (Castel, 1998, p. 27). As condições históricas metamorfoseiam a questão social, a qual é inerente ao processo de acumulação capitalista. Iamamoto (2007), importante referência no campo, destaca que "o predomínio do capital fetiche conduz à banalização do ser humano, [...] o que se encontra na raiz das novas configurações da questão social" contemporânea. De modo que, a questão social, além de ser expressão da pobreza, miséria, exclusão, vulnerabilidade e risco, condensa a banalização do humano, atestando à alienação "na era do capital fetiche" (Iamamoto, 2007, p. 125).

Neste sentido, as desigualdades, as expressões da questão social como objetos de intervenção do Serviço Social demarcam as políticas de escolarização não somente contemporâneas, mas históricas. Assim, a existência do "dualismo perverso das escolas públicas brasileiras" como uma aprendizagem que satisfaz necessidades mínimas, com uma visão restrita de competências 
básicas e reduzida a noções mínimas, apontam para essa perspectiva (Libâneo, 2012, p. 25). Da mesma forma que as políticas de escolarização atuais quase sistematicamente "negligenciam ou marginalizam a questão do conhecimento", apontando para a manutenção ou a multiplicação das desigualdades (Young, 2011, p. 395).

Percebe-se que Serviço Social e Educação possuem uma história e, mais do que isso, possuem um caminho de diálogo a ser construído, pois se o "dualismo" perpassa as escolas brasileiras, local onde, por excelência, se adquire o "conhecimento" (Libâneo, 2012; Young, 2011), logo, a emergência de profissionais do Serviço Social nessas políticas, intervindo diretamente nas expressões da questão social, pode otimizar o dualismo e possibilitar melhor aquisição do conhecimento?

Para melhor ordenar essa analítica, buscar-se-á enfatizar alguns pontos principais. Primeiramente serão considerados aspectos referentes à gênese do Serviço Social no Brasil, delineando algumas exterioridades dessa emergência. Um segundo aspecto remete a pontuações históricas da Educação brasileira, trazendo sinalizações precedentes à emergência do Serviço Social. Os dois pontos anteriores permitem adentrar com maior profundidade no terceiro aspecto, o qual abordará "a relação Educação e Serviço Social: sinalizações de um diálogo em emergência”, abrangendo o período de 1930-1990. Como aspecto sequencial, será dada ênfase à intensificação dessas relações a partir de 1990. Salienta-se que a intenção do presente texto está em tecer considerações acerca da historicidade das relações entre Educação e Serviço Social, aprofundando o debate dessa temática, descrevendo e analisando as diferentes formas de intervenção social produzidas no período examinado.

\section{A emergência do Serviço Social no Brasil: delineando exterioridades}

Ao memorar aspectos históricos do Serviço Social na Educação brasileira, cabe pontuar determinados precedentes. Alguns estudos enfatizam que a inserção do Serviço Social na escola remete a meados de 1906, nos Estados Unidos, onde, em centros sociais, eram designadas visitadoras para realizar o elo com escolas de bairros, com o objetivo de constatar o motivo pelo qual as famílias 
não enviavam os filhos à escola, além de verificar a evasão escolar, o baixo aproveitamento e a inadaptação de crianças na escola. Na Europa, esse campo específico era incluído na especificidade de intervenções de assistentes sociais realizadas com "menores" (Vieira, 1977, p. 67).

Em escritos sobre $A$ base do Serviço Social, a pesquisadora norte-americana Harriett M. Bartlett enfatiza que, no final dos anos 1920, emergiram cinco campos de prática do Serviço Social: bem-estar social, menor, médico, psiquiátrico e escolar. No que se refere à realidade escolar, o Serviço Social voltava-se para os problemas de menores nos programas educacionais e na escola. Nesse campo "não havia um amplo corpo visível de conhecimento sobre o problema principal - por exemplo, a natureza do ensino e o processo educacional". Trabalhava-se com a "escola como instituição" e com "o menor e sua família" de forma separada (Bartlett, 1970, p. 19).

No contexto latino-americano, as primeiras sinalizações do Serviço Social remetem a meados de 1925, quando "foi criada a primeira escola dessa especialidade em Santiago, no Chile”. Salienta-se que, nessa época, o Serviço Social se estabelecia como "subprofissão de médicos e advogados" em que o objetivo desses profissionais era obter maior eficiência e rentabilidade. Posteriormente, instituições de beneficência passaram a estimular essa profissão (Castro, 2000, p. 30). O surgimento das escolas de Serviço Social em si não subentende um processo que identifique como início da profissão. "A fundação das primeiras escolas - 1925, Chile; 1936, Brasil; 1937, Peru — apenas revela momentos específicos de um processo de maturação que atinge um ponto qualitativamente novo quando a profissão começa a colocar sua própria reprodução de modo mais sistemático" (Castro, 2000, p. 35). A gênese do Serviço Social na América Latina se deu no acentuado desenvolvimento capitalista, em que se pautava o processo de industrialização e, com ele, a miserabilidade, o crescimento urbano caótico, as migrações, possibilitando um espaço fértil para a proliferação desses profissionais (Castro, 2000).

Convém sinalizar que o Serviço Social latino-americano se firmou sobre bases e influências europeias, sendo que essa influência não foi exclusiva nesse campo. Um amplo terreno de relações estruturais da vida social era mantido entre os dois continentes nos mais variados campos e setores da sociedade 
(Castro, 2000). Essa influência se cristalizou por meio das classes dominantes, do Estado e da Igreja. Nas configurações específicas do Serviço Social visualiza-se uma "subordinação estrutural", pois se colocava à margem das relações de produção e suas consequências sociais e se recorria a experiências europeias ou, então, em anos posteriores, norte-americanas, como é o exemplo dos métodos de grupo e de comunidade propostos pela norte-americana Mary Richmond (Castro, 2000, p. 41).

Evitando procrastinações, pontua-se que, de aproximadamente 1925 a 1940, no Serviço Social latino-americano, nota-se a decisiva influência externa de países como a Bélgica, a França ou a Alemanha e, a partir da década de 1940, uma exclusiva influência norte-americana (Castro, 2000). Recorre-se novamente à metáfora da "astúcia da história". Nos aspectos mencionados até o momento - processo de industrialização e as fortes transformações societárias latino-americanas e, com ela a efervescência daquilo que se compreende como questão social —, o Serviço Social manteve uma postura acrítica, preocupado em apreender métodos terapêuticos, clínicos, individualizados, advindos de realidades externas. Dando continuidade à presente historicização, propõe-se, antes de elencar aspectos históricos de meados de 1930 na relação Serviço Social e Educação, realizar algumas pontuações anteriores referentes à realidade educacional brasileira, possibilitando uma visualização prévia e mais clarificada dos aspectos educacionais que antecederam a emergência do Serviço Social.

\section{Pontuações históricas da Educação brasileira: aspectos precedentes à emergência do Serviço Social}

Apreender a herança da qual a situação atual é herdeira quiçá seja um elemento indispensável para transgredir a história, no sentido de assumir uma forma diferente de ver e compreender a realidade atual, uma história que não diz tudo, que é apenas uma ínfima parte de uma herança repleta de entraves, emaranhados e astúcias (Castel, 1998; Koike, 2009). Nessa perspectiva, estudos sinalizam que a Educação, ou então o processo de escolarização, emergiram em meados de 1549, no contexto da consolidação do modelo agroexportador 
dependente, período em que a Companhia de Jesus adentrou em território brasileiro com a incumbência de escolarizar, tendo como moldes a educação europeia. Esse período de escolarização perdurou por aproximadamente 210 anos, até meados de 1759, momento em que os jesuítas foram expulsos do Brasil. De modo que aquilo que havia sido construído em relação à Educação foi desestruturado (Ribeiro, 2010).

Pontua-se que em praticamente "três séculos de colonização (1500-1822), os portugueses construíram um enorme país dotado de unidade territorial, linguística, cultural e religiosa". Em contrapartida, haviam também deixado um povo analfabeto e escravo; uma economia monocultural e latifundiária; um Estado absolutista, onde algumas pessoas exerciam poderes absolutos sobre a sociedade. De modo que, na proclamação da independência, "não havia cidadãos brasileiros, nem pátria brasileira" (Carvalho, 2002, p. 18). Assim, avança-se desde a independência (1822) até o final da Primeira República (1929), período em que a colonização portuguesa continuou deixando "marcas duradouras", remetendo ao entendimento daquilo que se denomina "peso do passado" (Carvalho, 2002). Até a independência o Brasil contava com "cerca de 3 mi1hões de escravos", sendo que a população era de aproximadamente "5 milhões [...]. Era tão grande a força da escravidão que os próprios libertos, uma vez livres, adquiriam escravos" (Idem, p. 19).

Convém frisar que em meados de "1872, meio século após a independência, apenas $16 \%$ da população era alfabetizada" (Carvalho, 2002, p. 23). A escola brasileira "brilhava pela ausência" (Carvalho, 1998, p. 240). Com a queda da monarquia e a Proclamação da República (1889), o sistema político teve alterações (Carvalho, 2002). O projeto político da República previa uma educação para todos, mas a escola ainda tinha dois princípios opostos: um estudo voltado para a elite (continuidade dos estudos, preparação para o curso superior) e o outro voltado para o povo (Aranha, 2006). Mesmo o Estado iniciando discussões acerca da educação popular, percebe-se que o "dualismo perverso", a diferenciação da educação dada aos ricos e aos pobres, é uma produção histórica (Libâneo, 2012).

Destaca-se que, a partir de 1890, algumas iniciativas de reforma da Educação foram surgindo: Benjamin Constant liderou a chamada reforma educacional, com princípios de liberdade do ensino, ensino laico e escola primária 
gratuita, conforme previa a Constituição brasileira. Posteriormente, outras reformas no sistema de ensino foram ocorrendo, no intuito de melhorar a Educação do país. Dentre elas destaca-se: Código Epitácio Pessoa, em 1901; a Reforma Rivadávia, em 1911; a Reforma de Carlos Maximiliano, em 1915; a Reforma de Luís Alves/Rocha Vaz, em 1925 (Beisegel, 1995).

Mesmo com iniciativas de reformas educacionais, entre meados de 1900 a 1920 , a taxa de analfabetismo no Brasil era de $75 \%$ entre as pessoas com quinze anos ou mais. Da preocupação com essa realidade iniciaram-se campanhas de disseminação das escolas primárias, com o intuito de combater o analfabetismo. Nesse período, permanece a intensa desigualdade no ensino: o ensino primário era bastante defasado, o atendimento escolar era precário, não havia nível que separasse por idade ou adiantamento, somente um professor numa sala de aula lecionava a todos os alunos do primário, o que gerou um aumento do analfabetismo. Isso ocorria porque não havia possibilidade de atender a todos os estudantes (Ribeiro, 2010).

No período que compreende a Primeira Guerra Mundial, entre 1910 a 1920, a educação brasileira vivenciou algumas experiências advindas de espanhóis e italianos, que trouxeram para o Brasil ideias revolucionárias, pois desejavam uma educação que atendesse a todos, inclusive os filhos de operários. Como resultado dessas ideias, foram fundadas algumas escolas que tinham como principais objetivos instaurar o ensino laico, a educação integral. No entanto, com a repressão do governo da época, as escolas fundadas diferentes das tradicionais eram fechadas, acusadas de serem perturbadoras da ordem (Aranha, 2006). Este período foi marcado pela diversidade de ideologias e de propostas ligadas à Educação, todas a fim de promover um Brasil diferente. O mais importante dos chamados pioneiros da educação nova, Anísio Teixeira, discípulo de Dewey, insistiam na ideia de que a educação era direito universal, instrumento de democratização da sociedade e de formação de cidadãos (Carvalho, 1998).

Em breve retomada, nota-se que durante aproximadamente quatro séculos de história, de acordo com os dados do censo de 1920, o Brasil contava com cerca de "30 milhões de habitantes", e destes apenas "24\% sabiam ler e escrever" (Carvalho, 2002, p. 65). Manteve-se nesse vasto período a "dualidade de sistemas", uma forma de ensino voltada para as classes privilegiadas e outra 
para o povo em geral (Beisegel, 1995). Assim, até meados de 1930 perdura no Brasil uma incapacidade histórica de reduzir as desigualdades, de democratizar a educação e de torná-la igualitária, tendo presente que iniciativas e movimentos contraditórios existiram em suas diferentes formas e expressões.

\section{A relação Educação e Serviço Social: sinalizações de um diálogo em emergência}

Destacadas algumas pontuações históricas acerca da Educação brasileira e, na busca de resgatar traços de origem da relação entre Educação e Serviço Social, sinaliza-se que essa articulação começa a ocorrer no Brasil em meados de 1930, mais precisamente em 1936, quando se instala a primeira escola de Serviço Social (Castro, 2000; CFESS, 2011). Portanto, a relação tem início desde a origem dos processos sócio-históricos constitutivos da profissão. No entanto, "é a partir da década de 1990, em consonância com o amadurecimento do projeto ético-político profissional, que se visualiza no Brasil um considerável aumento da inserção do Serviço Social na área da Educação" (CFESS, 2011, p. 5). Assim, nessa subseção, serão sinalizados aspectos preponderantes, que referenciam a emergência da relação Educação e Serviço Social, no período 1930-1990. Deste modo, adentrar na realidade da década de 1930, quando a Educação e o Serviço Social iniciam um diálogo, implica saber que esse período foi "um divisor de águas na história do país" (Carvalho, 2002, p. 87).

Os marcos iniciais do Serviço Social (1936) se deram em um período sinuoso, em que a Educação brasileira perpassava por um processo de democratização, com extensão das oportunidades de acesso à escola, em todos os níveis de ensino (Beisegel, 1995). Durante esse tempo, percebe-se uma forte repressão do Estado ao movimento proletário que se organizava. No campo político, o clima era fértil em pressões sociais pela melhoria da educação pública, bem como para a formação dos trabalhadores. Destacam-se o Manifesto dos Pioneiros (1932) e o movimento da educação nova, apontando para a necessidade de um Sistema Educacional Público (Krawczyk, 2012). A prerrogativa era propiciar o ensino a todos, independente de classe social. De acordo com Aranha (2006, p. 304), o documento elaborado pelo manifesto "defendia a educação obrigatória, pública, 
gratuita e leiga como dever do Estado, a ser implantada em programa de âmbito nacional". Contudo, a educação não era colocada como prioridade; "na visão dominante, o exercício dos trabalhadores agrícolas, prescindia até mesmo a alfabetização" (Krawczyk e Vieira, 2008).

Prescritivamente, a Constituição de 1934 orientava para a centralização das questões de ensino, em que o governo central deveria fixar um Plano Nacional de Educação (art. 150), criando Conselhos Nacionais e Estaduais de Educação (art. 152), de modo que essa constituição sinalizou para uma política nacional de educação, traçando diretrizes de ensino (Beisegel, 1995). Em 1953, no segundo mandato de Vargas, houve a separação entre as ações da Educação e da Saúde. A Lei n. 1.920 estabeleceu especificidade ao chamado Ministério da Educação e Cultura. Continuamente, no governo de Juscelino Kubitschek (1956-61), um debate importante referente à educação brasileira entrou em pauta: a Lei de Diretrizes e Bases (LDB). Esse debate foi precedido pelo Manifesto de 1959, que, diferente do de 1932, tratou de questões gerais referentes às políticas de escolarização. Destaca-se a atuação do professor Florestan Fernandes, que, junto a outros professores, buscaram fomentar discussões pelo interior do Brasil. Todavia, tanto a LDB de 1961 quanto a de 1971 não trouxeram mudanças radicais à realidade educacional brasileira (Ghiraldelli, 2009).

De modo que o período ditatorial (1964-85) deixou heranças para a educação: políticas de escolarização, movimentos sindicais, reivindicações, greves de professores, as várias conferências de educação. Porém as problemáticas deixadas por esse sistema foram bastante intensas. Em 1983, o país contava com mais de 60 milhões de analfabetos e semiletrados para uma população de aproximadamente 130 milhões de pessoas (Ghiraldelli, 2009). Esse dado revela a forte dificuldade no processo de democratização do ensino e da extensão das oportunidades de acesso à escola.

Muito embora a educação estivesse presente na agenda política, a partir de 1930, a devida preocupação com a mesma não se traduziu em projetos que norteassem os estados da federação, tampouco em práticas políticas. Tanto que as promessas de expansão de ensino técnico foram reduzidas e transferidas para a iniciativa privada. Assim, na primeira metade do século XX houve uma desresponsabilização do Estado nacional pelo ensino primário, que foi sendo 
gradativamente assumido pelos estados mais industrializados da federação. "A forte mobilização pela Educação ocorrida na década de 1980, que acompanhou a luta pela democratização da sociedade, demonstra que esse cenário não tinha mudado substancialmente [...] tais demandas encontraram respaldo nos preceitos da CF de 88" (Krawczyk e Vieira, 2008, p. 50).

Evidencia-se um terreno educacional, com ensaios de expansão e democratização, perpassando por entraves descontínuos de melhorias, de modo que o Serviço Social em sua emergência no Brasil encontrou um ambiente tênue, contraditório não somente em aspectos educacionais, mas em todo contexto societário. Há sinalizações de que já nas duas primeiras décadas do século XX, diante das fortes mobilizações da classe operária, debates sobre a "questão social" perpassaram todas as esferas da sociedade, em que o Estado determinava que a classe dominante, em conjunto com a Igreja, tomasse posição diante de tais mobilizações. O Serviço Social emerge da iniciativa dessas frações dominantes e é mobilizado a trabalhar com a formação doutrinária e com os problemas sociais de forma apaziguadora (Iamamoto, 2000).

Percebe-se que a evolução do Serviço Social no Brasil, mediante um Estado paternalista, "foi fator condicionante da montagem de um sistema de instituições sociais que propunham solucionar os problemas através de programas assistenciais de caráter imediatista" (CBCISS, 1986, p. 24). Nesse momento histórico vivenciado pelo Serviço Social denominado "conservadorismo", as ações, desenvolvidas por tais profissionais, eram favoráveis à manutenção da ordem capitalista (Iamamoto, 2000, p. 25). Algumas produções científicas referendando as interfaces entre Educação e Serviço Social foram sendo construídas. Um exemplo é a obra Serviço Social, infância e juventude desvalidas, de 1939 (reeditada em 1985), na qual a assistente social Maria Esolina Pinheiro aborda ideias e técnicas do Serviço Social nas diferentes áreas de atuação. $\mathrm{Na}$ especificidade escolar, o Serviço Social aparece como um espaço de "ação social", em que devia se prestar subsídios de informações sobre a vida dos alunos (Pinheiro, 1985, p. 43).

Em 1940, é produzido um número significativo de trabalhos de conclusão de curso descrevendo a intervenção do Serviço Social no espaço ocupacional educacional. "No acervo bibliográfico das primeiras escolas de Serviço Social 
do país constata-se a requisição, por parte do Estado, de uma intervenção sistematizada do profissional de Serviço Social junto à Educação e mais especificamente junto à escola" (Witiuk, 2004, p. 27). A tese da assistente social Ilda Lopes Witiuk constata, em investigação realizada nas quatro primeiras escolas de Serviço Social no Brasil, 223 trabalhos de conclusão de curso produzidos sobre o tema, sendo o primeiro datado de 1944, e outras 156 publicações (artigos, dissertações, anais etc.) produzidas até o ano de 2000 (Witiuk, 2004).

Uma referência, nesse período, é o trabalho de Maria Tereza Guilherme, Serviço Social Escolar, publicado em 1945 pela Imprensa Oficial do Estado de São Paulo, em que se identifica a perspectiva da unidade família, Igreja e Estado. A autora destaca como atribuição do Serviço Social no espaço da escola, "curar e prevenir desajustamentos, contribuir com eficiência em todos os setores escolares para o desenvolvimento harmonioso e integral da criança, [através de] métodos adequados" (1945, p. 79).

As ações exercidas por esses profissionais, frutos de uma herança, de influências externas e de interesses governamentais, são percebidas nas primeiras intervenções desenvolvidas em âmbito educacional. Amaro (2011), ao relatar sobre a institucionalização do Serviço Social escolar no Brasil, ressalta que "o mais antigo registro de que temos conhecimento do Serviço Social educacional remete ao estado do Rio Grande do Sul, quando foi implantado como serviço de assistência escolar na antiga Secretaria de Educação e Cultura, em 25 de março de 1946, por meio do Decreto n. 1.394". Nesse serviço, os assistentes sociais eram chamados para "intervir em situações escolares consideradas desvio, defeito ou anormalidade social" (Amaro, 2011, p. 19). Outra experiência da inserção de Assistentes Sociais no espaço escolar, no estado de Pernambuco, reafirma que a ação profissional estava voltada para "resolver problemas como evasão, repetência, desmotivação, dificuldades nos relacionamentos, absenteísmo às aulas e demais desconfortos escolares". A exigência ao profissional era que o mesmo "ajustasse os desajustados, ajudasse os necessitados, integrasse os alunos à sociedade" (Souza, 2005, p. 34).

Reitera-se a visibilidade de que, no percurso da gênese do Serviço Social (1936), até meados de 1970, se perpetua, de um modo geral, ações conservadoras em todos os âmbitos da atuação profissional. O processo de ruptura se 
intensifica devido a inúmeros fatores ligados à ineficácia profissional e à ações paliativas ou imediatistas. "Contestadores levantaram a bandeira da "reconceituação" no início dos anos 1960, levando para o Serviço Social os questionamentos de outras disciplinas sociais, políticas e econômicas, que se localizavam principalmente nas universidades" (CBCISS, 1986, p. 8).

Nesse movimento histórico, outra produção científica pode ser ressaltada, referendando o Serviço Social e a Educação. Em 1968, ao investigar sobre as "Fallas de Desenvolvimiento en la escuela publica: un enfoque de servicio social de grupo", os pesquisadores Vinter e Sarri discorreram sobre problemáticas referentes à evasão escolar, fracasso, insuficiência e a dificuldade na aprendizagem. Esse estudo aponta que a má conduta dos alunos, interferindo nas aulas e na disciplina escolar, eram questões voltadas para o Serviço Social (Souza, 2005, p. 31).

A intervenção do Serviço Social no espaço educacional seguia a "lógica desenvolvimentista voltada para a preparação social dos indivíduos, a fim de torná-los, segundo suas aptidões, cidadãos produtivos e úteis ao capital" (Amaro, 2011, p. 19). Ao Serviço Social bastava: examinar a realidade social e econômica dos alunos e das famílias; identificar situações de desajuste social; orientar professores, pais e alunos sobre esses desajustes; fazer triagem de alunos que necessitassem de material escolar, transporte, entre outros; elaborar relatórios de suas ações; articular escola e comunidade; orientar comunidades e famílias na responsabilidade quanto ao processo educativo dos filhos (Amaro, 2011). De modo que o processo de reconceituação do Serviço Social brasileiro foi um período ímpar, propiciando maior aproximação aos movimentos sociais e a perspectivas teóricas críticas. Os debates se ampliaram no interior da categoria profissional, abrangendo todos os espaços sócio-ocupacionais, sendo possíveis visualizações e iniciativas de mudanças (Iamamoto, 2000).

Aconteceram quatro seminários importantes para a categoria profissional: “em 1967, na cidade mineira de Araxá, sobre teorização do Serviço Social; em 1970, em Teresópolis, Rio de Janeiro, sobre metodologia do Serviço Social”; em 1978, em Sumaré, também no Rio de Janeiro, sobre "cientificidade do Serviço Social"; e mais tarde, em 1984, em Alto da Boa Vista, ressaltando o debate sobre a teorização do Serviço Social (CBCISS, 1986, p. 8). Entre o seminário 
de Teresópolis e o de Sumaré destaca-se outra obra referendando o Serviço Social e a Educação, do pedagogo, filósofo e sociólogo argentino, Ander-Egg, publicada em 1974, intitulada El trabajo social como acción liberadora. Nela, o autor referenda os vários campos de atividade nos quais os assistentes sociais exerciam algum tipo de trabalho, inclusive na Educação, em que o profissional visava fortalecer as relações entre escola e família, integrar as crianças que tinham dificuldades de adaptação à vida escolar e desenvolver um trabalho articulado com outros profissionais que atuavam na escola (Ander-Egg, 1974).

Os seminários referendados foram intensos em reflexões inscritas no processo de renovação do Serviço Social no Brasil. O esforço era no sentido de adequar o Serviço Social "enquanto instrumento de intervenção inserido no arsenal de técnicas sociais a ser operacionalizado no marco de estratégias de desenvolvimento capitalista, às exigências postas pelos processos sociopolíticos emergentes no pós-64" (Netto, 1996, p. 154). Ressalta-se também que, mediante o enfraquecimento do regime militar na segunda metade da década de 1970, há a ascensão do marxismo acadêmico, sendo que na década de 1980 a perspectiva de intenção de ruptura aproxima-se da universidade, espaço que "se apresentava como menos adverso que os outros para apostas de rompimento" (Netto, 1996, p. 250).

As aproximações realizadas pelo Serviço Social (1970 e 1980) com as matrizes teóricas que destacavam os movimentos sociais, as lutas de classes e a "questão social" enquanto categorias de análises fundamentais para a compreensão da realidade social fazem com que — a partir da década de 1990 — tais temas sejam estudados com maior densidade por meio de um conjunto de tendências teórico-metodológicas na direção da tradição marxista (Iamamoto, 2008). Neste movimento, ressalta-se a renomada importância do viés investigativo que passa a ser incorporado na profissão dos Assistentes Sociais.

Por certo, ocorreu grande esforço nas décadas de 80 e 90 em fortalecer a base científico-profissional difundida, principalmente, através do processo de desconstrução e reconstrução crítica da profissão e de seu exercício, fundando-se no aporte sócio-histórico da análise do real, que foi disseminado pelo então "novo" currículo de formação da década de 80 (Sposati, 2007, p. 17). 
A construção da nova cultura crítica, no interior da profissão, foi corroborada por um conjunto de fatores sócio-históricos. Nos aspectos até então pontuados salienta-se: a inquietação da própria categoria profissional quanto à teorização; a cientificidade da prática profissional; a abertura à pesquisa; a ascensão do marxismo acadêmico; o enfraquecimento do regime militar, entre outros aspectos que foram sinalizando para a ruptura, para a reconstrução crítica da intervenção profissional.

Na interface Educação e Serviço Social pontua-se que, na segunda metade da década de 1980 e início dos anos 1990, ambos perpassavam por um processo de reconfiguração. O processo de democratização se intensifica a partir de 1985, trazendo conquistas expressas na Constituição de 1988, a qual foi pautada por debates, pressões e movimentos populares, ampliando o escopo dos direitos sociais (Krawczyk e Vieira, 2008). Na Constituição Federal de 1988, Educação e Serviço Social (assistência social) fazem parte do Título VIII, denominado "Da ordem social", tendo por base o primado do trabalho e como objetivo o bem-estar e a justiça social. A partir dessa Constituição, a Assistência Social passa a ser parte integrante da Seguridade Social juntamente com a Saúde e a Previdência (art. 194); seguidamente é prestada a quem dela necessitar. No que tange à Educação, a CF de 1988a afirma como direito de todos e dever do Estado e da família (art. 205), elencando os princípios do ensino (art. 206), entre outros delineamentos (Brasil, 1988).

A constituinte de 1988 aprovou a "Constituição mais liberal e democrática que o país já teve, merecendo por isso o nome de Constituição Cidadã" (Carvalho, 2002, p. 199). Mesmo com tal conquista, em aspectos democráticos, não se pode dizer que havia uma estabilidade, haja vista persistirem problemas econômicos sérios, como as desigualdades e o desemprego. Os problemas da área social, sobretudo na Educação, nos serviços de saúde e saneamento continuavam. Assim, "os cidadãos brasileiros chegam ao final do milênio, quinhentos anos após a conquista dessas terras pelos portugueses e 178 anos após a fundação do país, envoltos num misto de esperança e incerteza" (Carvalho, 2002, p. 200).

Essa mescla de esperança e incertezas pode ser visualizada nos dados do relatório do Banco Mundial de 1989, em que o Brasil aparece como o país mais 
desigual do mundo. Mesmo tendo diminuído o número de analfabetos, havia em 1990 cerca de 30 milhões de brasileiros de cinco anos de idade ou mais que eram analfabetos. Segundo pesquisas do Instituto de Pesquisa Econômica Aplicada (Ipea), a desigualdade econômica brasileira cresceu ligeiramente entre 1990 e 1998. "A escandalosa desigualdade" tem como consequência situações críticas de pobreza e de miserabilidade. "Tomando-se a renda de setenta dólares - que a Organização Mundial da Saúde (OMS) considera ser o mínimo necessário para a sobrevivência - como a linha divisória da pobreza, o Brasil tinha, em 1997, 54\% de pobres" (Carvalho, 2002, p. 208). O que significa que, em uma população de 160 milhões, 85 milhões de pessoas eram pobres ou então miseráveis.

Saliento a ênfase realçada nesta analítica: permanece, de acordo com cada momento histórico, a incapacidade do sistema representativo de produzir resultados que impliquem a redução da desigualdade (Carvalho, 2002); a "questão social", compreendendo seus desdobramentos e suas "metamorfoses" (Castel, 1998), dá indícios de intensificação em meados de 1990. Mesmo com um cenário político de conquistas de direitos sociais, dados pressupostos da Constituição de 1988, a desigualdade é alarmante: mais de metade da população brasileira se encontrava em situação de pobreza, com forte contingente de analfabetos.

4.1 Intensificação das relações entre Educação e Serviço Social: um enfoque a partir de 1990

É instigante pensar as formas com que as questões do Serviço Social começam a adquirir relevância e espaço nas políticas de escolarização brasileiras. Esse estímulo ocorre, não somente, mas inclusive, por considerar que a inserção desses profissionais na Educação teve início aproximadamente na década de 1930, de forma passiva, e apenas em meados de 1990, ou seja, depois de sessenta anos, há uma movimentação significativa, abrindo espaços de maior inserção (Souza, 2005). Essa intensificação é caudatária dos avanços e acúmulos teóricos da profissão nas discussões em torno das políticas sociais como lócus privilegiado da ação profissional (Almeida, 2003). Nesse sentido, “o campo educacional torna-se, hoje para o assistente 
social, não apenas um futuro campo de trabalho, mas sim um componente concreto do seu trabalho em diferentes áreas de atuação que precisa ser desvelado" (Almeida, 2000, p. 74). Essa perspectiva denota a possibilidade de uma ampliação teórica, política e instrumental da própria atuação do Serviço Social e de sua vinculação às lutas sociais que se expressam na esfera da cultura e do trabalho (Almeida, 2000).

Possivelmente, a emergência desses novos profissionais nas políticas de escolarização assinala-se pela imbricada afinidade existente dessas políticas com temáticas referentes à proteção social, riscos sociais, vulnerabilidade social, seguridade, programas e benefícios assistenciais. Essa relação ingressou definitivamente na agenda de composição das políticas de escolarização brasileiras contemporâneas (Tiramonti, 2005; Dussel, 2009). Neste sentido, e considerados os processos históricos até então pontuados, num cenário contraditório de ampliação dos direitos sociais, dados os preceitos da Constituição de 1988, convém destacar a forte emergência de uma gama de políticas públicas que inferem diretamente em questões voltadas à Educação e ao Serviço Social.

O Estatuto da Criança e do Adolescente (ECA) aprovado em 1990, que dispõe sobre a "proteção integral" à criança e ao adolescente, estabelece uma política específica de atendimento dos direitos da criança e do adolescente, a qual movimenta um conjunto articulado de ações governamentais envolvendo Judiciário, Ministério Público, Defensoria, Segurança Pública, Assistência Social, Educação, entre outros mecanismos (Brasil, 1990). O projeto ético-político profissional do Serviço Social consolidado no Código de Ética Profissional do Assistente Social (1993) e na Lei da Regulamentação da Profissão de Serviço Social, Lei n. 8.662, de 1993, juntamente com a Lei Orgânica da Assistência Social (Loas), n. 8.742, de 1993. Este conjunto normativo ressalta a perspectiva crítica adotada pela categoria profissional, tendo como princípios fundamentais a defesa dos direitos humanos, a ampliação e consolidação da cidadania, a equidade, a justiça social. Tais legislações demarcam a autonomia profissional e o compromisso ético-político desses profissionais com a classe trabalhadora, definindo a assistência social, como direito do cidadão e dever do Estado, que prove os mínimos sociais, num conjunto integrado de ações (Iamamoto, 2008). Em aspectos educacionais há o respaldo da Lei de Diretrizes e 
Bases (LDB) n. 9.394, de 1996, a qual disciplinou a educação escolar vinculando-a ao mundo do trabalho e à prática social.

Retomando a dinâmica histórica, nos últimos anos as oportunidades de acesso e permanência no sistema escolar se expandiram paulatinamente, tanto que ao final do século XX o ensino fundamental obrigatório estava praticamente universalizado no que diz respeito ao acesso. A tensão que permanece faz referência à garantia da qualidade do ensino. Além do atendimento à demanda por mais educação, há o direito à educação de qualidade para amplos contingentes da população ou sua negação, "o que pode tornar inócua a democratização do acesso, quer seja por sua distribuição diferenciada, quer seja por, e também, relegar a qualidade a nichos de privilégio no interior do sistema educacional" (Oliveira, 2007, p. 666).

Nesse âmbito, na década de 1990, foi "reincorporada parcela substantiva de alunos anteriormente excluídos ou que não haviam ainda ingressado no sistema escolar" (Oliveira, 2007, p. 668). A LDB de 1996 contribuiu para tal reincorporação, ao especificar a possibilidade de adoção de mecanismos como os ciclos, a aceleração de estudos, a recuperação paralela e a reclassificação, entre outras medidas indicadas nos arts. 23, 24 e 32. Percebe-se que "no período de 1980 a 2000, o percentual da população de sete a catorze anos que estava no sistema escolar passa de 80 para $96,4 \%$ e na faixa de quinze a dezessete anos, de 49,7 para 83\%". Esse acesso começa a se generalizar, também, para o ensino médio, permitindo que determinadas parcelas da população, pela primeira vez, concluam com sucesso o ensino fundamental (Oliveira, 2007, p. 680).

Simultaneamente à tensão para garantir a qualidade da educação, percebe-se o crescente interesse dos assistentes sociais pela área, como objeto de pesquisa e como campo interventivo (CFESS, 2011). Em 2000, o Projeto de Lei n. 3.688, que dispõe sobre a inserção do assistente social e do psicólogo no quadro de profissionais de Educação, foi apresentado na Câmara dos Deputados. Apesar de ter recebido voto de rejeição em 2001, o projeto tramitou até o ano de 2007 na Comissão de Educação e Cultura (CEC) e na Comissão de Constituição, Justiça e Cidadania (CCJC), sendo aprovado e encaminhado ao Senado, transformando-se no Projeto de Lei da Câmara (PLC) n. 060, de 2007 (CFESS, 2012). 
Em novembro de 2009, o PLC n. 060/2007 foi aprovado, após passar por algumas alterações, como a mudança da expressão, que no projeto original constava "profissionais de assistência social", e passou para "profissionais de Serviço Social". De acordo com o PLC n. 060/2007, em seu artigo primeiro, as redes públicas de educação básica contarão com serviços de Psicologia e do Serviço Social para atender às necessidades e prioridades definidas pelas políticas de escolarização, por meio de equipes multiprofissionais. Tais equipes deverão desenvolver ações voltadas para a melhoria da qualidade do processo de ensino-aprendizagem, com a participação da comunidade escolar, atuando na mediação das relações sociais e institucionais.

Atualmente o Projeto de Lei está aguardando parecer na Comissão de Educação e Cultura (CEC), sendo que, se aprovado, seguirá para a Comissão de Constituição, Justiça e Cidadania (CCJC). Após aprovação de ambas as comissões, o PL seguirá para ser votado pelos deputados e então sancionado pela presidente. De acordo com o deputado José Carlos Elias, a atuação de assistentes sociais na Educação terá reflexos na diminuição da evasão escolar e servirá de apoio à ação dos professores, trazendo como resultado sensíveis melhorias nos níveis de aprendizagem dos estudantes (CFESS, 2012).

Assim, o trabalho desenvolvido pelos assistentes sociais, em que pese a dimensão socioeducativa de suas ações, tem se dado no sentido de fortalecer as redes de sociabilidade e de acesso aos serviços sociais e dos processos socioinstitucionais voltados para o reconhecimento e aplicação dos direitos dos sujeitos sociais (Santos, 2012). Outro aspecto relevante na intensificação das relações entre Educação e Serviço Social foi a composição, em 2001, do Grupo de Estudos sobre o Serviço Social na educação, por intermédio do CFESS, o qual construiu o subsídio intitulado "Serviço Social na Educação" (CFESS, 2011, p. 5). Em 2010, esse grupo de estudos apontou a necessidade de assessoria para aprofundar o debate, tendo, a partir de então, o assessoramento do prof. Ney Luiz Teixeira de Almeida, o qual já vinha acompanhando essa trajetória (CFESS, 2011). Deve-se salientar que a inserção de profissionais do Serviço Social nas políticas de escolarização não visa somente "identificar um nicho de mercado inexplorado ou potencialmente viável" à categoria do Serviço Social. Ao contrário, 
trata-se, antes de tudo, de um campo de intervenção do Estado e de uma dimensão da vida social, que hoje se coloca como estratégia na sociedade contemporânea, seja para a afirmação de um projeto societário vinculado aos interesses do capital, seja para a ampliação e integração das lutas no que diz respeito à conquista de direitos e enfrentamento das desigualdades (Almeida, 2000, p. 24).

No mesmo sentido, o documento "Serviço Social na educação" destaca a necessidade de compreender a educação como "uma política social que tem o compromisso de garantir direitos sociais. Indica também uma reformulação e/ou ampliação do conceito de educação, que precisa ser assimilada a partir da perspectiva de sua produção social e do papel que a escola assume na sociedade" (CFESS, 2001, p. 8). Assim, em 2011, o GT elaborou o documento "Subsídios para o debate sobre Serviço Social na educação", com o objetivo de auxiliar nas discussões do assunto e dar continuidade ao documento "Serviço Social na educação" (CFESS, 2011). Em junho de 2012, também foi realizado o I Seminário Nacional de Serviço Social na Educação, que debateu sobre "os elementos teóricos e políticos da relação Serviço Social e Educação, bem como as possibilidades, limites e polêmicas da inserção e atuação do Serviço Social nesta área" (Santos et al., 2012, p. 11).

\section{Algumas considerações}

Os aspectos abordados apontam para a notável intensificação das relações entre Educação e Serviço Social a partir de 1990. No entanto, tal intensificação, além de fazer parte de uma pauta de luta da categoria profissional do Serviço Social para o reconhecimento legislatório nessa área de atuação, soma-se a outros fatores, a saber, "nas últimas décadas, as transformações societárias em curso em nível mundial engendradas pelo capital, às quais impõem processos de reforma neoliberal do Estado, que incidem sobre as políticas sociais e, em particular, sobre a Política de Educação como direito social" (CFESS, 2012, p. 248).

De maneira pontual e objetiva considera-se que na constituição histórica das relações entre Serviço Social e Educação ocorreram significativas mudan- 
ças de ênfase nas racionalidades políticas e nas formas de intervenção ao longo do último século. Ainda que o debate sobre as proteções sociais e o combate às desigualdades seja uma constante, pode-se notar que há uma intensificação, a partir da década de 1990, não somente da ampliação da relação Educação e Serviço Social, mas sobretudo da prerrogativa que abarca as prevenções do risco social, numa lógica de proteção social.

Em síntese, podem ser notadas, nesse estudo, três modalidades de ação profissional interventiva: uma terapêutica (primeiro momento), outra comunitária (segundo momento), e uma terceira, que abarca as prevenções do risco e vulnerabilidade social, numa lógica de proteção social (terceiro momento, a partir da CF 1988). Convém respaldar que essas mudanças nas modalidades de articulação entre as duas áreas, sobretudo no âmbito das políticas de escolarização, reforçam uma leitura aproximada das mudanças na própria questão social. De fato, conforme pontuado no decorrer deste estudo, a inserção do Serviço Social na Educação é um espaço que necessita ser desvelado, no sentido de compreender as nuances dessa inserção.

Enfim, retomando a metáfora com a qual teve início este estudo, "astúcia da história", (Koike, 2009), a ênfase analítica "desigualdades sociais, distância social, metamorfoses da questão social" (Carvalho, 2002; Sennett, 2006; Castel, 1998), como objetos de intervenção do Serviço Social e presentes historicamente nas políticas de escolarização, retorna-se ao objetivo analítico. Buscou-se, no decorrer do desenvolvimento textual, tecer considerações que mobilizem o entendimento de que os aspectos históricos da relação entre Educação e Serviço Social foram permeados de tensões constantes, as quais provocaram significativas mudanças nas ênfases e racionalidades políticas interventivas. Neste sentido, o viés abordado instiga novas investigações, no sentido de perceber as estratégias políticas que são mobilizadas por intermédio das políticas de escolarização.

Recebido em 4/9/2014 Aprovado em 24/11/2014 


\section{Referências bibliográficas}

ALMEIDA, Ney Luiz Teixeira. Educação pública e serviço social. Serviço Social \& Sociedade, São Paulo, n. 63, 2000.

. Serviço Social e política educacional: um breve balanço dos avanços e desafios desta relação. In: I ENCONTRO DE ASSISTENTES SOCIAIS NA ÁREA DA EDUCAÇÃO, Belo Horizonte, mar. 2003. Disponível em: <http://www.cress-mg.org.br/ arquivos/Servi\%C3\%A7o-Social-e-pol\%C3\%ADtica-educacional-Um-breve-balan $\% \mathrm{C} 3 \% \mathrm{~A} 7 \mathrm{o}$-dos-avan $\% \mathrm{C} 3 \% \mathrm{~A} 7 \mathrm{os}-\mathrm{e}$-desafios-desta-rela $\% \mathrm{C} 3 \% \mathrm{~A} 7 \% \mathrm{C} 3 \% \mathrm{~A} 3 \mathrm{o}$. pdf>. Acesso em: 20 fev. 2014.

AMARO, Sarita. Serviço Social na educação: bases para o trabalho profissional. Florianópolis: Ed. da UFSC, 2011.

ANDER-EGG, Ezequiel. El trabajo social como acción libertadora. Buenos Aires: Editorial Librería Ecro, 1974.

ARANHA, Maria Lúcia de Arruda. História da educação e da pedagogia. 3. ed. São Paulo: Moderna, 2006.

BARTLETT, Harriett M. A base do Serviço Social. Tradução Margarida Luzzi Pizante Filha. 2. ed. São Paulo: Livraria Pioneira Editora, 1970.

BEISEGEL, Celso. Educação e sociedade no Brasil após 1930. In: FAUSTO, Boris (Org.). História geral da civilização brasileira. Rio de Janeiro: Bertrand do Brasil, 1995. t. III, v. 4, p. 383-416.

BRASIL. Constituição da República Federativa do Brasil. Brasília: Senado Federal, 1988 .

. Lei n. 8.069, de 13 de julho de 1990. Dispõe sobre o Estatuto da Criança e do Adolescente e dá outras providências. Diário Oficial da União, Brasília, 13 jul. 1990.

CARVALHO, José Murilo de. Pontos e bordados: escritos de história e política. Belo Horizonte: Ed. da UFMG, 1998.

. Cidadania no Brasil: o longo caminho. 3. ed. Rio de Janeiro: Civilização Brasileira, 2002.

CASTRO, Manuel Manrique. História do Serviço Social na América Latina. Tradução José Paulo Netto e Balkys Villalobos. 5. ed. rev. São Paulo: Cortez, 2000. 
CASTEL, Robert. As metamorfoses da questão social: uma crônica do salário. Tradução Iraci D. Poleti. Petrópolis: Vozes, 1998.

CBCISS (Centro Brasileiro de Cooperação e Intercâmbio de Serviços Sociais). Teorização do Serviço Social. 2. ed. Rio de Janeiro: Agir, 1986.

CFESS. Serviço Social na Educação. GT Serviço Social na Educação. Brasília: CFESS/ CRESS, 2001.

. Subsídios para atuação de assistentes sociais na política de educação. $G T$ Serviço Social na Educação. Brasília: CFESS/CRESS, 2011.

. PL Educação é aprovado na Comissão de Seguridade da Câmara. Brasília, 2012. Disponível em: $<$ http://www.cfess.org.br/noticias_res.php?id=773>. Acesso em: 26 mar. 2014.

DUSSEL, Inés. A transmissão cultural assediada: metamorfoses da cultura comum na escola. Cadernos de Pesquisa, São Paulo, v. 39, n. 137, maio/ago. 2009.

GHIRALDELLI JUNIOR, Paulo. História da educação. 4. ed. São Paulo: Cortez, 2009. GUILHERME, Maria Teresa. Serviço Social escolar. São Paulo: Imprensa Oficial do Estado, 1945.

IAMAMOTO, Marilda Villela. O Serviço Social na contemporaneidade: trabalho e formação profissional. 2. ed. São Paulo: Cortez, 1999.

. Renovação e conservadorismo no serviço social. 5. ed. São Paulo: Cortez, 2000.

. Serviço Social em tempo de capital fetiche: capital financeiro, trabalho e questão social. São Paulo: Cortez, 2007.

. Serviço Social em tempo de capital fetiche. 3. ed. São Paulo: Cortez, 2008.

KOIKE, Maria Marieta. Formação profissional em Serviço Social: exigências atuais. In: Serviço Social: direitos sociais e competências profissionais. Brasília: CFESS/ ABEPSS, 2009.

KRAWCZYK, Nora. A historicidade da pesquisa em política educacional: o caso do Brasil. Jornal de Políticas Educacionais, Curitiba, n. 12, jul./dez. 2012.

; VIEIRA, V. L. A reforma educacional na América Latina: uma perspectiva histórico-sociológica. São Paulo: Xamã, 2008. 
LIBÂNEO, José Carlos. O dualismo perverso da escola pública brasileira: escola do conhecimento para os ricos, escola do acolhimento social para os pobres. Educação e Pesquisa, São Paulo, v. 38, n. 1, 2012.

NETTO, José Paulo. Ditadura e Serviço Social: uma análise do Serviço Social no Brasil pós-64. 3. ed. São Paulo: Cortez, 1996.

OLIVEIRA, Romualdo Portela de. Da universalização do Ensino Fundamental ao desafio da qualidade: uma análise histórica. Educ. Soc., Campinas, v. 28, n. 100 - Especial, p. 661-690, out. 2007.

PINHEIRO, Maria Esolina. Serviço Social: infância e juventude desvalidas (documento histórico). São Paulo: Cortez; Rio de Janeiro: Centro de Produção da UERJ, 1985.

RIBEIRO, Maria Luísa Santos. História da educação brasileira: a organização escolar. 21. ed. Campinas: Autores Associados, 2010.

SANTOS, et al. A inserção do Serviço Social na política de educação na perspectiva do conjunto CFESS/Cress: elementos históricos e desafios para a categoria profissional. SER Social, Brasília, v. 14, n. 30, p. 244-258, jan.jun. 2012.

SANTOS, Nelma Souza dos. Serviço Social e educação: contribuições do assistente social na escola. 2012. Disponível em: $<$ http://www.reitoria.uri.br/vivencias/Numero_015/artigos/pdf/Artigo_10.pdf>. Acesso em: 12 jun. 2014.

SENNETT, Richard. A cultura do novo capitalismo. Tradução Clóvis Marques. Rio de Janeiro: Record, 2006.

SEVERINO, Antonio Joaquim. Fundamentos ético-políticos da educação no Brasil de hoje. In: LIMA, J. C.; NEVES, L. M. (Orgs.). Fundamentos da educação escolar no Brasil contemporâneo. Rio de Janeiro: Fiocruz, 2006. p. 289-320.

SOUZA, Iris de Lima. Serviço Social e educação: uma questão em debate. Interface, Natal, v. 2, n. 1, jan./jun. 2005.

. Dimensão educativa do assistente social na dimensão escolar. Disponível em: $<$ http://www.servicosocialnaeducacao.info/wpcontent/uploads/2012/06/Dimens\% C3\%A3o-educativa-do-assistente-social-naeduca $\% \mathrm{C} 3 \% \mathrm{~A} 7 \% \mathrm{C} 3 \% \mathrm{~A} 30-$-escolar.pdf $>$. Acesso em: 26 ago. 2013.

SPOSATI, Aldaíza. Pesquisa e produção de conhecimento no campo do Serviço Social. Katálysis, Florianópolis, v. 10, número especial, p. 15-25, 3 abr. 2007. 
TIRAMONTI, Guillermina. La escuela en la encrucijada del cambio epocal. Educação \& Sociedade, Campinas, v. 26, n. 92, p. 889-910, especial, out. 2005.

VIEIRA, Balbina Ottoni. História do Serviço Social: contribuição para a construção de sua teoria. Rio de Janeiro: Agir, 1977.

WITIUK, I. L. A trajetória sócio-histórica do Serviço Social no espaço da escola. Tese (Doutorado em Serviço Social) — Pontifícia Universidade Católica, São Paulo, 2004.

YOUNG, Michael. O futuro da educação em uma sociedade do conhecimento: a defesa radical de um currículo disciplinar. Cadernos de Educação, Pelotas, n. 38, p. 395-416, jan./abr. 2011. 